\title{
Preparation and Characterization of Ti-15Mo Alloy used as Biomaterial
}

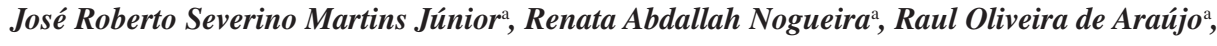 \\ Tatiani Ayako Goto Donato ${ }^{\mathrm{b}}$,Vitor Elias Arana-Chavez, Ana Paula Rosifini Alves Claro ${ }^{\mathrm{c}}$, \\ João Carlos Silos Moraes , Marília Afonso Rabelo Buzalaf', Carlos Roberto Grandinia,"* \\ ${ }^{a}$ UNESP - Univ. Estadual Paulista, Laboratório de Anelasticidade e Biomateriais, \\ CEP 17033-360, Bauru, SP, Brazil \\ ${ }^{\mathrm{b}} U S P$, Departamento de Biologia Oral, CEP 05508-900, São Paulo, SP, Brazil \\ ${ }^{\circ}$ UNESP - Univ. Estadual Paulista, Departamento de Materiais e Tecnologia, \\ CEP 12516-410, Guaratinguetá, SP, Brazil \\ ${ }^{\mathrm{d}}$ UNESP - Univ. Estadual Paulista, Faculdade de Engenharia, \\ Departamento de Física e Química, CEP 15385-000, Ilha Solteira, SP, Brazil \\ ${ }^{\mathrm{e}} U S P$, Faculdade de Odontologia, Departamento de Ciências Biológicas, \\ CEP 17012-901, Bauru, SP, Brazil
}

Received: December 9, 2010; Revised: February 15, 2011

\begin{abstract}
With the increase in life expectancy, biomaterials have become an increasingly important focus of research because they are used to replace parts and functions of the human body, thus contributing to improved quality of life. In the development of new biomaterials, the Ti-15Mo alloy is particularly significant. In this study, the Ti-15Mo alloy was produced using an arc-melting furnace and then characterized by density, X-ray diffraction, optical microscopy, hardness and dynamic elasticity modulus measurements, and cytotoxicity tests. The microstructure was obtained with $\beta$ predominance. Microhardness, elasticity modulus, and cytotoxicity testing results showed that this material has great potential for use as biomaterial, mainly in orthopedic applications.
\end{abstract}

Keywords: Ti-Mo alloys, elasticity modulus, biomaterials, vacuum melting

\section{Introduction}

Commercially pure titanium and its alloys are used largely as structural biomaterials in the fabrication of orthopedic and dental implants due to their excellent properties of high mechanical strength and corrosion resistance ${ }^{1,2}$. However, studies have shown that the liberation of aluminum and vanadium ions present in alloys such as Ti-6Al-4V and Ti-6Al-7Nb can cause some health problems over the course of time. It is known that aluminum ions cause neurological disorders, and vanadium ions are associated with enzymatic disturbers, among others problems ${ }^{3,4}$.

Because of these problems, it is necessary to look for alternatives with more biocompatibility, similar mechanical strength, corrosion resistance, smaller elasticity modulus, and hardness in order to promote efficient cicatrization and osseo remodeling, thus avoiding prostheses loss. The research to date on titanium-based alloys used as biomaterial concentrated on those of the $\beta$-type because the processing variables can be controlled to produce alloys with better properties such as smaller elasticity modulus and high corrosion resistance. In addition, osseo tissue responds better to $\beta$-type alloys than to $(\alpha+\beta)$-type alloys ${ }^{5,6}$.

Alloys of the binary Ti-Mo system were studied by several researchers. Ho et al. ${ }^{7}$ studied a series of binary Ti-Mo alloys using $\mathrm{X}$-ray diffraction, optical microscopy, microhardness, and elasticity modulus, showing that the microstructure of the alloy is strongly dependent on the molybdenum content. In another paper, Ho et al. ${ }^{8}$ made a comparison between the cp-Ti, Ti-7.5Mo, Ti-15Mo and Ti-6Al-4V, with respect of mechanical properties and corrosion resistance, showing that the Ti-15Mo alloy has elasticity modulus smaller than the cp-Ti and Ti-6Al-4V, but higher than Ti-7.5Mo alloy; the Ti-15Mo alloy showed the best value of corrosion potential and Ti-7.5Mo showed similar values to $\mathrm{cp}-\mathrm{Ti}$. Chen ${ }^{9}$ studied the microstructure and mechanical properties of alloys Ti-Mo system containing 5, 10, 15 and $20 \%$ in weight of molybdenum by X-ray diffraction measurements and showed that the crystalline structure is dependent on the molybdenum concentration. Concerning the mechanical properties such as hardness, compression strength, elasticity modulus and compression ratio, the author observed that as the concentration of molybdenum increases, the compression strength and hardness decreases; for elasticity modulus, a reduction ocuurs, but from $20 \mathrm{wt}$. (\%) of molybdenum, the modulus increases. Oliveira et al. ${ }^{10}$ studied a set of binary alloys of Ti-Mo, making an analysis of the microstructure and electrochemical characterization. Microstrutural analysis showed results similar to Ho et al. ${ }^{7}$ and the results of electrochemical characterization showed good corrosion resistance in all studied alloys. Niinomi ${ }^{11}$ studied mechanical properties such as elasticity modulus, fatigue, and mechanical strength for various titanium alloys, including the Ti-15Mo alloy. $\mathrm{He}$ observed how the martensitic transformation of the $\beta$ phase changes the multifunctional properties of the studied alloys.

Ti-15Mo stands out among the Ti-Mo system alloys due to not only its excellent corrosion resistance but also its good combination of mechanical properties such as fatigue, hardness, and wear resistance. In this way, a better understanding of the application of Ti-15Mo's main properties to biomaterial becomes quite feasible. 
This paper presents a study of the preparation, processing, and characterization of the Ti-15Mo alloy with a view to its use as a biomaterial.

\section{Experimental Part}

The alloy was obtained from the melting of the pure elements in an arc-melting furnace in a controlled atmosphere using a nonconsumable electrode and water-cooled copper crucible. The samples were re-melted almost five times to guarantee homogenization. After the melting process, the ingots were submitted to hot swaging, by which cylindrical rods with $4.0 \mathrm{~mm}$ of diameter and $60.0 \mathrm{~mm}$ of length were obtained.

The samples in the two processing conditions, after melting and after hot-swaging, were characterized by chemical composition, density, X-ray diffraction, optical microscopy, Vickers microhardness, and elasticity modulus measurements.

The chemical composition of the samples was verified by LaserInduced Breakdown Spectroscopy (LIBS), Varian. Analysis of oxygen and nitrogen were made by fusion in inert gas, in addition to infrared detection for oxygen and thermal conductivity difference for nitrogen using gas analyzer LECO TC-400 equipment.

The density measurements were obtained by using an Explorer model Ohaus precision balance and density determination kit, which is based on Archimedes' principle. Each density value represents the average of five measures.

The phases were analyzed using a Rigaku D/Max 2100 PC X-ray diffractometer with $\mathrm{Cu}-\mathrm{K}_{\alpha}(\lambda=1.544 \AA$ ) radiation, current of $20 \mathrm{~mA}$ and $40 \mathrm{kV}$ potential, step of 0.02 degrees and time of 1.6 seconds, range $20^{\circ}$ to $100^{\circ}$ in the fixed time mode. The measurements were made using the powder method and the samples were honed to obtain powder. The microstructural analyses were made using an Olympus BX51M microscope.

The microhardness measurements were performed in a Shimadzu model HMV-2, using a load of 200 gf (1.96 N) by 60 seconds. For each sample, five measurements were made in different positions. The values of microhardness test match average of ten measurements.

The dynamic elasticity modulus was obtained by mechanical spectroscopy measurements using the torsion pendulum technique operating in the frequency range of $4-30 \mathrm{~Hz}$, with the temperature between 100 and $700 \mathrm{~K}$ and vacuum better than $10^{-6} \mathrm{mbar}$, in which it is possible to measure the damping of the free vibrations of the system, related to the elastic energy loss (internal friction), and the oscillation frequency, $f$, associated to the elasticity modulus, $E$, by the following equation ${ }^{12,13}$ :

$$
E=\frac{32}{3} \pi^{2} \Lambda I f^{2}
$$

where $I$ is the inertia momentum of the system and $\Lambda$ is the constant shape of a sample with a circular cross-section, given by ISO 6721-2 standard $^{12}$ :

$$
\Lambda=\frac{32 L}{\pi d^{4}}
$$

where $L$ and $d$ are the utile length and diameter of the sample, respectively.

To verify the biocompatibility of the prepared samples, in vitro cytotoxicity tests-MTT modified and analysis in scanning electron microscope (SEM)-were conducted. For these tests, osteogenic cells of the MC3T3-E1 lineage (pre-osteoblasts from thickened calvarium mouse newborns-ATCC) were utilized, which were cultivated on the titanium alloy for 72 hours (MTT test) and 24 hours (SEM analysis). It was used eight samples of Ti-15Mo after each processing condition, based on ISO 10993-5 standard ${ }^{14}$, with a diameter of about $4 \mathrm{~mm}$ and a thickness of $1 \mathrm{~mm}$, were weighed so that the amounts were calculated from the culture medium MEM- $\alpha$, needed for the direct cytotoxicity test.

The modified $\mathrm{MTT}^{15}$ assesses the reduction ability of tetrazolium salt (3-bromide [4,5-dimetilthiazol-2-yl]-2,5-difeniltetrazólio) (MTT, $5 \mathrm{mg} . \mathrm{mL}^{-1}$ PBS - Sigma-Aldrich) by the mitochondrial enzyme Succinato desidrogenases to fromazan crystals at the end of the reaction. Since the MTT is a colorimetric test, the yellow MTT solution changes to purple when it reacts with the mitochondrial enzyme. The intensity of this reaction can be quantified by a spectrophotometer reading that measures absorbance at $562 \mathrm{~nm}$ using a microplate reader. For testing direct cytotoxicity, the cells were plated under the surface of the material. A polystyrene (culture plate) was used as the negative control, and a solution of $\alpha$-MEM, $10 \%$ of FBS, and $1 \%$ of phenol was used as the positive control. To MTT analysis was done in triplicate with $n=5$. The results were analyzed statistically by ANOVA test complemented with Tukey's test. The level of significance was $5 \%(\mathrm{p} \leq 0.05)$.

To corroborate the results of cell viability, the osteoblasts were cultivated on the alloy for 24 hours. After 24 hours, the cells were fixed in $4 \%$ paraformaldehyde $+0.1 \%$ glutaraldehyde buffered with sodium cacodylate, $\mathrm{pH} \mathrm{7.2,} \mathrm{for} 1$ hour at room temperature and routinely processed for scanning electron microscopy. Samples were examined post-fixed with $1 \%$ osmium tetroxide, dehydrated in crescent concentrations of ethanol and desiccated after treatment with HMDS. Specimens were mounted onto aluminum stubs, sputtered with gold and examined in a JEOL 6100 scanning electron microscopy. Cells grown on a glass coverslip were used as negative control ${ }^{16}$.

\section{Results and Discussion}

The chemical composition of the prepared samples is presented in Table 1. It can be observed that there is a small difference between the nominal value (15 wt. (\%)) and the measured molybdenum quantity. This difference can be explained by the small variations of molybdenum concentration along of the sample. The ASTM F 2066-08 standard ${ }^{17}$ for Ti-15Mo requires that the molybdenum concentration must be between 14.00 and 16.00 (wt. (\%)). Hence, the prepared alloy is in accordance with this standard.

Table 2 shows the results of the gas analysis for the samples after the melting (Ti-15Mo\#0) and after the hot swaging (Ti-15Mo\#1). The ASTM F 2066-08 standard $^{17}$ requires a maximum content of $(0.20 \pm 0.02)$ and $(0.05 \pm 0.02)$ for oxygen and nitrogen, respectively. Table 2 shows that the values presented are lower than those established by the standard. Therefore, the results of chemical composition and gas analysis indicate that the preparation of the alloy was adequate.

The X-ray diffractograms for the samples measured after the melting (Ti-15Mo\#0) and after the hot swaging (Ti-15Mo\#1) compared with commercially pure titanium are presented in Figure 1.

Table 1. Chemical composition of the Ti-15Mo samples after melting.

\begin{tabular}{cccccc}
\hline Element & Mo & $\mathrm{Cr}$ & $\mathrm{Fe}$ & $\mathrm{Ni}$ & $\mathrm{Ti}$ \\
\hline wt. $(\%)$ & 14.47 & 0.008 & 0.024 & 0.007 & balance \\
\hline
\end{tabular}

Table 2. Gas analysis for the Ti-15Mo samples in all studied conditions.

\begin{tabular}{lcc}
\hline Sample & Oxygen (wt. (\%)) & Nitrogen (wt. (\%)) \\
\hline Ti-15Mo\#0 & $0.137 \pm 0.005$ & $0.006 \pm 0.002$ \\
Ti-15Mo\#1 & $0.177 \pm 0.004$ & $0.007 \pm 0.002$ \\
\hline
\end{tabular}


By the peaks position is possible to identify that $\mathrm{cp}$-Ti possess only hexagonal structure, known as $\alpha$ phase. The produced Ti-15Mo alloy has two different crystal structures, hexagonal and body-centered cubic, $\alpha$ ' and $\beta$ phase, respectively ${ }^{7,10}$. With the addition of $15 \mathrm{wt}$. (\%) molybdenum, the crystal structure of $\mathrm{cp}$-Ti changes from hexagonal to body centered cubic, predominantly. The peaks of the hexagonal structure in the Ti-15Mo alloy were identified as $\alpha$, martensitic phase, formed by rapid cooling processes. For the melting process, it was used a water cooled copper crucible, causing a rapid cooling in the region of contact with the crucible, allowing the appearance of the $\alpha$ ' phase. During the hot swaging, the alloy was heating up to working temperature in a resistive furnace (temperature between 780-860 ${ }^{\circ} \mathrm{C}$ ), and then, after the reduction of its dimensions, was cooled in air, which is considered a rapid cooling to occur $\alpha$ ' phase retention. The peaks intensity changed after the hot swaging and this effect can be associated with the phases concentration ${ }^{18}$.

The diffractogram of the sample after the melting (Ti-15Mo\#0) shows that the peaks of the $\alpha^{\prime}$ phase have small intensity. This fact indicates that this phase is present in small quantities in the microstructure. In the sample after the hot swaging (Ti-15Mo\#1), the peaks of the $\alpha$ ' phase are more intense, indicating an increase of this phase in the microstructure due to the thermo-mechanical processing to which the sample was submitted (hot swaging). The sample was heated around $850{ }^{\circ} \mathrm{C}$, and its cooling made possible the retention of the $\alpha$ ' phase. The obtained results are in accordance with the studies of Ho et al. ${ }^{7}$, Oliveira et al. ${ }^{10}$, and Bania et al. ${ }^{19}$, where the authors affirm that a minimum of $10 \mathrm{wt}$. (\%) of molybdenum is necessary for the predominance of the $\beta$ phase at room temperature.

The optical micrographies of the samples after melting (Ti-15Mo\#0) and after hot swaging (Ti-15Mo\#1) are presented in Figure 2 and are in accordance with those obtained by Ho et al. and Kumar and Narayanan ${ }^{20}$. The results for the samples after melting (Ti-15Mo\#0) show well-defined grain boundaries and a predominance of $\beta$ matrix (Figure 2a) in accordance with X-ray measurements for this sample. Figure $2 b$ shows the results after hot swaging (Ti-15Mo\#1), indicating a different grain conformation with the irregular shape, characteristic of materials that undergo a thermomechanical processing and a subsequent fast cooling, in which the structure does not have sufficient time to accommodate a more stable configuration. The shaded regions in the micrographies are due to pitting corrosion caused by the acid solution that was used to reveal the microstructure, therefore, not characterizing a crystalline phase. It is not possible to verify the presence of $\alpha$ ' in the optical microscopy, probably due to low concentration of this phase in the microstructure.

Also indicated in the inter-grain region are structures that can be attributed to the $\alpha$ ' phase distributed inside the grain, which are in accordance with the X-ray diffractograms shown in Figure 1.

The obtained values for the density of the samples after melting (Ti-15Mo\#0) and after hot swaging (Ti-15Mo\#1) are presented in Table 3. It can be verified that the obtained value is very close to the theoretical value, $4.97 \mathrm{~g} . \mathrm{cm}^{-3}$, which is calculated from the atomic weights and theoretical densities of titanium and molybdenum ${ }^{21}$. This result is a very good indicator that the stoichiometry was respected and the prepared samples were homogeneous. In the case of the hot swaging sample (Ti-15Mo\#1), there was an increase in the density value that can be explained by the increase in the $\alpha$ ' phase and incorporation of impurities during processing. The $\alpha$ ' phase possesses a higher density than the $\beta$ phase because the packing factor of the hcp structure ( $\alpha$ ' phase) is approximately $9 \%$ higher than the bcc structure $(\beta \text { phase })^{22}$.

The Vickers microhardness for the samples after melting (Ti-15Mo\#0) and after hot swaging (Ti-15Mo\#1) is shown in Figure 3. The obtained values show that the molybdenum addition led to an

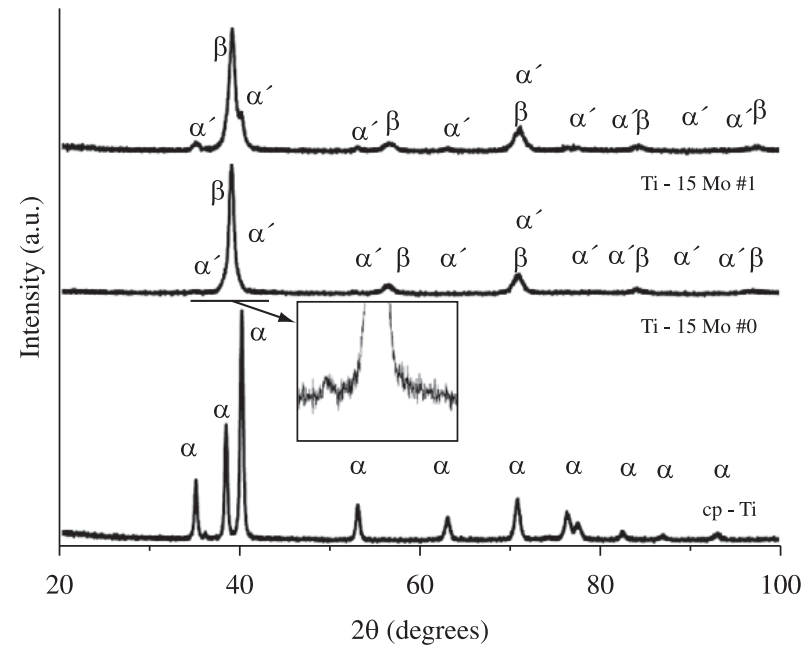

Figure 1. X-ray diffractograms for the Ti-15Mo samples after melting and after hot swaging, compared with cp-Ti.

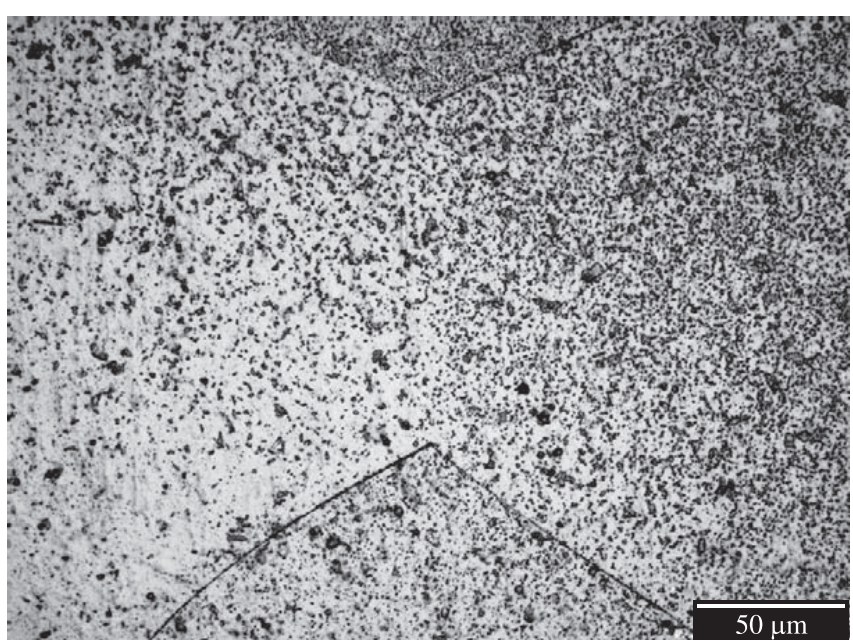

(a)

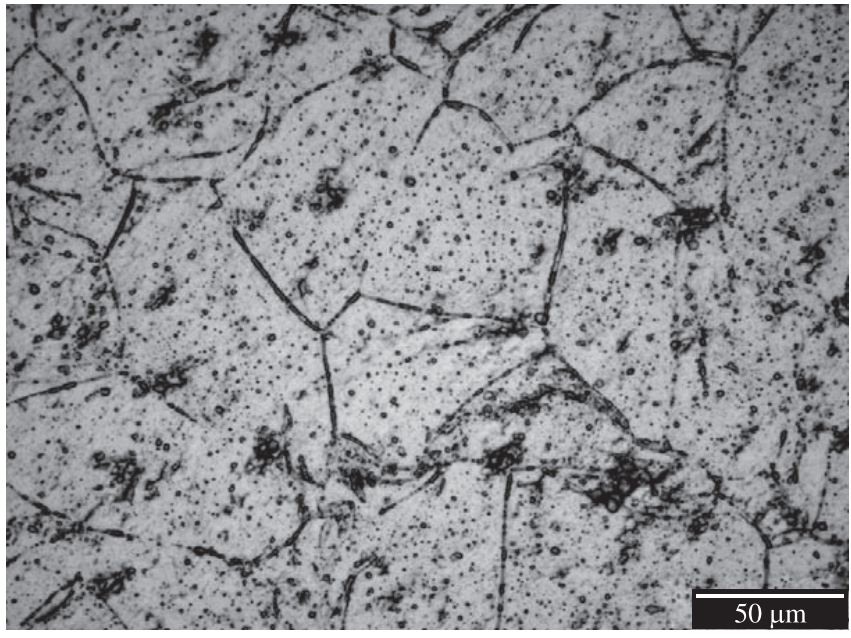

(b)

Figure 2. Optical micrographies for the Ti-15Mo samples after melting (a) and after hot swaging (b). 
increase in the hardness value when compared with $\mathrm{cp}-\mathrm{Ti}$, which was because the hardness of molybdenum is higher than that of titanium ${ }^{21}$. Figure 3 also presents a comparison of the results obtained in this paper with previously published studies in the literature ${ }^{23-25}$, showing good agreement with them.

Figure 3 also shows that the sample after hot swaging (Ti-15Mo\#1) presents a hardness value higher than after melting (Ti-15Mo\#0). This fact is due to the increase of the internal stresses caused by hot swaging. Moreover, the X-ray diffractograms of the samples after hot swaging showed peaks characteristic of the $\alpha$ ' phase, which have a hardness value higher than the $\alpha$ ' phase. Hence, according to the results, the tendency was to obtain more hardness in the hot swaging sample.

The $\omega$ phase, in Ti-Mo system, is characterized by the weakening of the material and has a tendency to decrease, among other mechanical properties, the hardness value ${ }^{25}$. Although there weren't measurements of transmission electron microscopy to investigate the possible presence of this phase, these effects weren't observed in this paper. This reinforces that the phase $\alpha$ ' is a major contributor to the increase in microhardness.

The Figure 3 also shows the results of microhardness compared with the paper of Nag et al. ${ }^{25}$. Nag, in his paper studied two processing conditions for the Ti-15Mo alloy, which were called (a) and (b). The condition (a) was homogenized at a temperature of $1100^{\circ} \mathrm{C}$ for 7 days and (b) after aging homogenized with a temperature of $600{ }^{\circ} \mathrm{C}$ for 4 hours and then cooled. The microhardness values of Ti-15Mo \#1, presented in this paper, when compared to the condition (a) are very close. In this condition, Nag et al. ${ }^{25}$ studied the microstructure using a scanning electron microscopy and the micrographies are very similar to the presented in this paper. In the condition (b) was observed the presence of $\omega$ phase using a transmission electron microscopy and

Table 3. Density values for the samples of the Ti-15Mo alloys.

\begin{tabular}{cc}
\hline Sample & $\rho\left(\mathrm{g} . \mathrm{cm}^{-3}\right)$ \\
\hline Ti-15Mo\#0 & $4.96 \pm 0.01$ \\
Ti-15Mo\#1 & $5.02 \pm 0.01$ \\
\hline
\end{tabular}

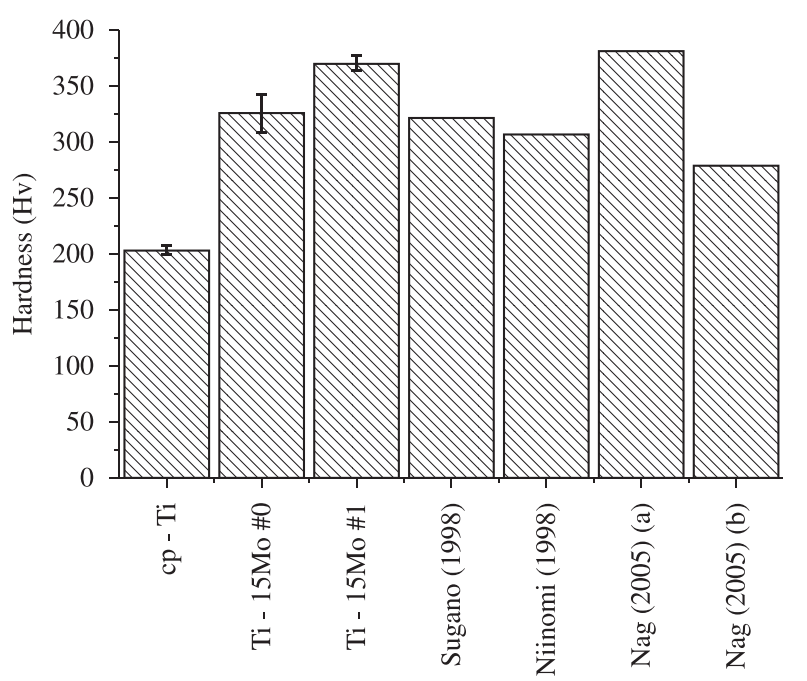

Figure 3. Vickers microhardness for the Ti-15Mo samples after melting and after hot swaging, compared with cp-Ti and with the literature. the decreasing in the microhardness value of the alloy was attributed to presence of this phase.

The dynamic elasticity modulus shown in Figure 4 was obtained by the torsion pendulum technique and, decreases when the temperature increases, which is characteristic of most metals, due to the natural softening that occurs with increasing heat ${ }^{22}$. The obtained value for the elasticity modulus is lower than that observed for cp-Ti. This value is in accordance with the literature, where the elasticity modulus of $\alpha$-type alloys is higher compared with $\beta$-type alloys ${ }^{1,6}$ because the atoms are closer in the hcp structure due to the high packing factor, making the intensity of the chemical bonds stronger ${ }^{22}$. Because the elasticity modulus is directly related to the intensity of these bonds, it will be higher for the $\alpha$ ' phase ${ }^{26}$.

Figure 5 shows a comparison of the elasticity modulus obtained at $37^{\circ} \mathrm{C}$ (body temperature) with results previously published in the literature ${ }^{7,24,25}$ and cp-Ti. In previous studies, the elasticity modulus of $\beta$-type alloys are between 55 and $124 \mathrm{GPa}^{1,6,25}$, which is in accordance with the results obtained for the Ti-15Mo in this study. These values are low in comparison with $\alpha$ or $(\alpha+\beta)$-type titanium alloys. However, these values are higher than those of the human bone, which are normally between 17 and $28 \mathrm{GPa}^{26}$.

Figure 6 shows the results of the direct cytotoxic test (cellular viability) for the Ti-15Mo samples after hot swaging (Ti-15Mo\#1), where the results of absorbance for the alloy are close to the negative control (negative cytotoxicity) and above the results of the cp-Ti and positive cytotoxicity control, indicating that the samples are not cytotoxic, i.e., are biocompatible. Figure 7 shows the SEM results, where the osteoblastic cells are spread, showing the success of cellmaterial interaction (Figure 7c), which can be seen in the studied controls, glass (Figure 7a) and cp-Ti (Figure 7b). Moreover, no modifications in the cellular morphology were observed, indicating that the material did not cause any type of aggression. These results, with those of cellular viability, suggest that the prepared alloy did not present any type of cytotoxic effect, i.e., it did not cause interference in the cellular growth or viability. Moreover, it did not cause any modification in the cell morphology or in its adhesion to the material surface $^{15,27}$.

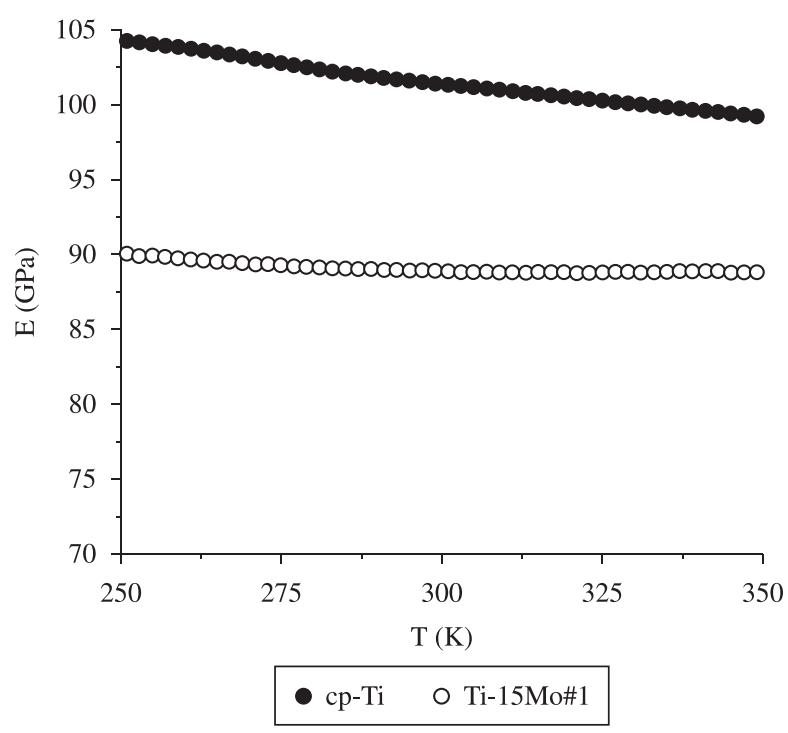

Figure 4. Dynamic Elasticity Modulus as a temperature function, for the Ti-15Mo sample after hot swaging, compared with cp-Ti. 


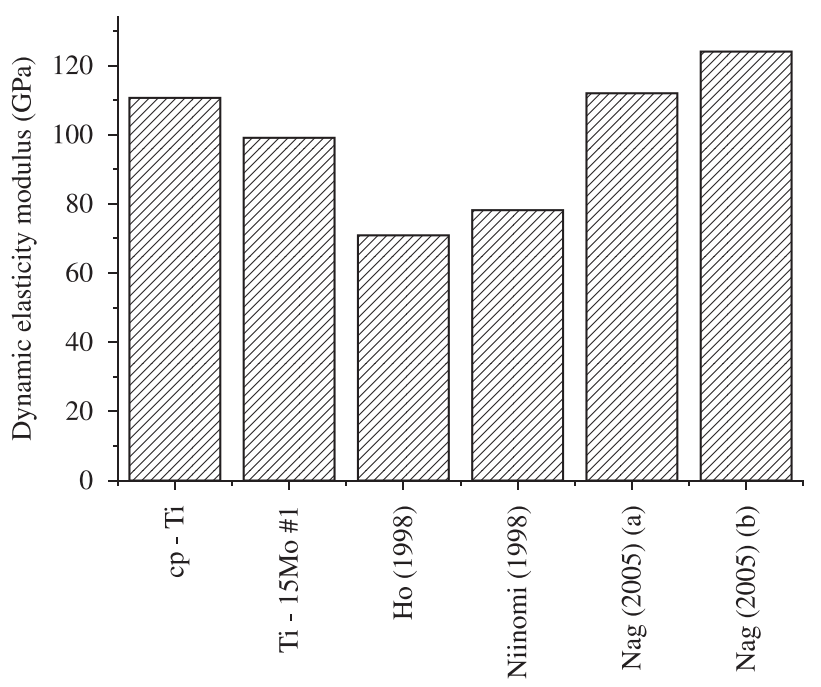

Figure 5. Dynamic Elasticity Modulus at $37^{\circ} \mathrm{C}$, for the Ti-15Mo sample after hot swaging, compared with cp-Ti and with the literature.

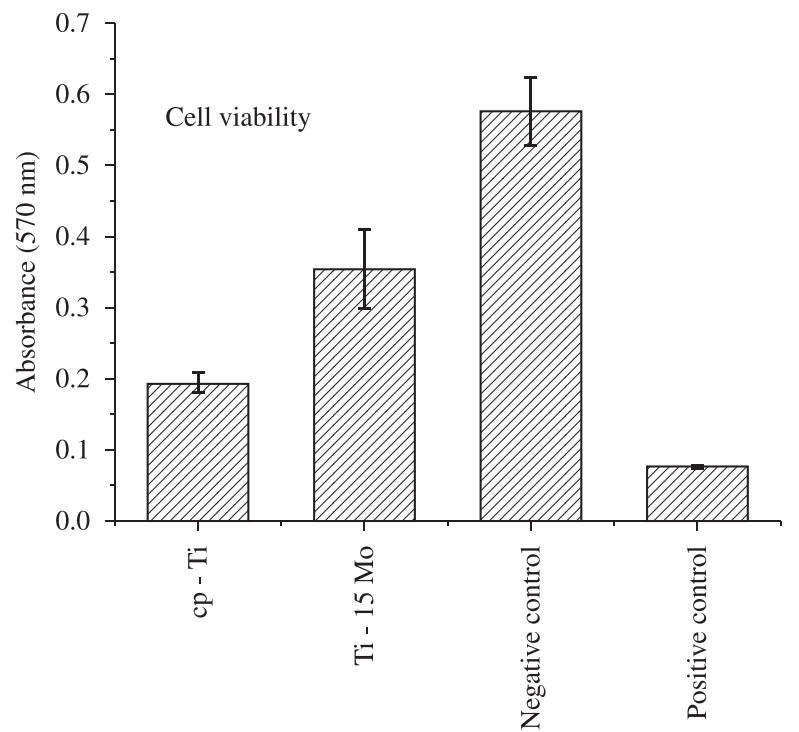

Figure 6. Cell viability for the Ti-15Mo alloy, after the hot swaging, compared with cp-Ti Positive control is a phenol solution and negative control is the culture plate.

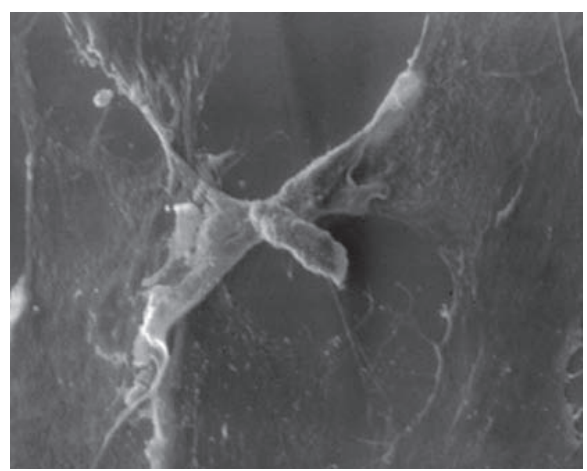

(a)

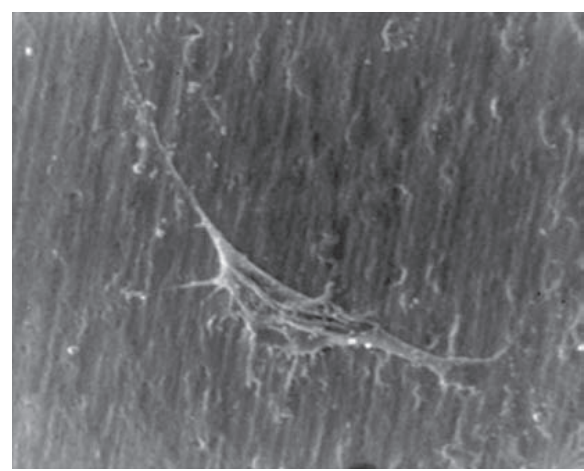

(b)

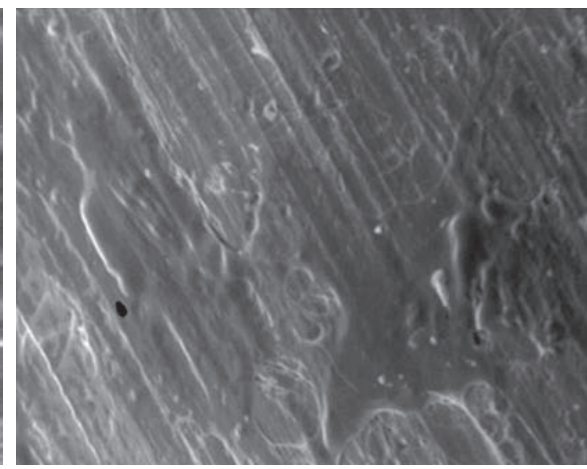

(c)

Figure 7. SEM for osteoblasts cells of MC3T3-E1 lineage on the control (glass plate) (a) cp-Ti (b) and Ti-15Mo alloy (c). Magnification of 900×.

\section{Conclusions}

In this paper, samples of the Ti-15 wt. (\%)Mo alloy were prepared by arc-melting and were characterized by chemical analyses, measurements of density, X-ray diffraction, optical microscopy, hardness, and elasticity modulus. Chemical analysis showed that the stoichiometry and amount of interstitial elements are in accordance with the ASTM F 2006-8 standard for this alloy. In X-ray diffraction measurements, it was observed that there were significant microstructural changes after the hot swaging with an increase in the intensity of the peaks of $\alpha^{\prime}$-phase of the alloy. Moreover, with addition of 15 wt. (\%) of molybdenum, there was an increment in density and microhardeness, and a reduction in the elasticity modulus when compared to $\mathrm{cp}$-Ti and $\beta$ types Ti alloys. Furthermore, with the addition of molybdenum it wasn't observed cytotoxic effects.

\section{Acknowledgements}

The authors thank Brazilian agencies FAPESP and CNPq for their financial support.

\section{References}

1. Geetha M, Singh AK, Asokamani R and Gogia AK. Ti based biomaterials, the ultimate choice for orthopaedic implants - A review. Progress in Materials Science. 2009; 54(3):397-425.

2. Niinomi M. Fatigue performance and cyto-toxicity of low rigidity titanium alloy, Ti-29Nb-13Ta-4.6Zr. Biomaterials. 2003; 24(16):2673-83.

3. Rao S, Ushida T, Tateishi T, Okazaki Y and Asao S. Effect of Ti, Al, and $\mathrm{V}$ ions on the relative growth rate of fibroblasts (L929) and osteoblasts (MC3T3-E1) cells. Biomedical Materials Engineering. 1996; 6(2):79-86.

4. Walker PR, LeBlanc J and Sikorska M. Effects of aluminum and other cations on the structure of brain and liver chromatin. Biochemistry.1989; 28(9):3911-5.

5. Niinomi M, Kuroda D, Fukunaga K-i, Morinaga M, Kato Y, Yashiro T et al. Corrosion wear fracture of new $\beta$ type biomedical titanium alloys. Materials Science and Engineering A. 1999; 263(2):193-9.

6. Nasab MB and Hassan MR. Metallic Biomaterials of Knee and Hip - A Review. Trends in Biomaterials and Artificial Organs. 2010; 24(1):69-82.

7. Ho WF, Ju CP and Chern Lin JH. Structure and properties of cast binary Ti-Mo alloys. Biomaterials. 1999; 20(22):2115-22. 
8. Ho WF. A comparison of tensile properties and corrosion behavior of cast Ti-7,5Mo with c.p, Ti-15Mo and Ti-6Al-4V alloys. Journal Alloys and Compounds. 2008; 464:580-3.

9. Chen Y. Microstructures and properties of titanium alloys Ti-Mo for dental use. Transactions of Nonferrous Metals Society of China. 2006; 16:824-6.

10. Oliveira NTC, Aleixo G, Caram R and Guastaldi AC. Development of Ti-Mo alloys for biomedical applications: Microstructure and electrochemical characterization. Materials Science and Engineering: A. 2007; 452-453:727-31.

11. Niinomi M. Mechanical biocompatibilities of titanium alloys for biomedical applications. Journal of the Mechanical Behavior of Biomedical Materials. 2008; 1:30-42.

12. International Organization for Standardization - ISO. Plastics Determination of Dynamic mechanical properties. Part 2: Torsion Pendulum method. ISO 6721-2. Genebra, Suíça: International Organization for Standardization; 1994.

13. Pintão CAF, Almeida LH and Grandini CR. Medida do Momento de Inércia de um Pêndulo de Torção para Estudo de Relaxações Anelásticas. Revista Brasileira de Aplicações de Vácuo. 2006; 25(4):189-92.

14. International Organization for Standardization - ISO. Biological evaluation of medical devices. Part 5: Test for cytotoxicity: in vitro methods. ISO 10993-5. Genebra, Suíça: International Organization for Standardization; 1994.

15. Donato TAG, Almeida LH, Nogueira RA, Niemeyer TC, Grandini CR, Caram R, et al. Cytotoxicity study of some Ti alloys used as biomaterial. Materials Science and Engineering: C. 2009; 29(4):1365-9.

16. Nanci A, Zalzal S, Gotoh Y, McKee MD. Ultrastructural characterization and immunolocalization of osteopontin in rat calvarial osteoblast primary cultures. Microsc. Res. Tech. 1996; 33:214-31.
17. ASTM. Standard specification for wrought titanium-15 molybdenum alloy for surgical implant application. ASTM F 2066-08. Philadelphia (USA): ASTM; 2008.

18. Howard CJ. Quantitative Phase Analysis from Neutron Powder Difraction Data Using the Rietveld Method. Journal Applied Crystallography. 1987; 20: 467-74.

19. Bania PJ. Beta Titanium Alloys and Their Role in the Titanium Industry. In: Eylon D, Boyer RR and Koss DA, editors. Titanium Alloys in the 1990's. Warrendale: The Mineral, Metals \& Materials Society; 1993.

20. Kumar S and Narayanan TSNS. Corrosion behaviour of Ti-15Mo alloy for dental implant applications. Journal of Dentistry. 2008;36(7):500-7.

21. Lide D. CRC handbook of chemistry and physics: a ready-reference book of chemical and physical data: CRC Press; 2004.

22. Callister W. Materials science and engineering: an introduction: John Wiley \& Sons; 2007.

23. Sugano M, Tsuchida Y, Satake T and Ikeda M. A microstructural study of fatigue fracture in titanium-molybdenum alloys. Materials Science and Engineering: A. 1998;243(1-2):163-8.

24. Niinomi M. Mechanical properties of biomedical titanium alloys. Materials Science and Engineering: A. 1998;243(1-2):231-6.

25. Nag S, Banerjee R and Fraser HL. Microstructural evolution and strengthening mechanisms in Ti-Nb-Zr-Ta, Ti-Mo-Zr-Fe and Ti-15Mo biocompatible alloys. Materials Science and Engineering: $C$. 2005;25(3):357-62.

26. Rho JY, Ashman RB and Turner CH. Young's modulus of trabecular and cortical bone material: Ultrasonic and microtensile measurements. Journal of Biomechanics. 1993;26(2):111-9.

27. Atala A and Lanza R. Methods of tissue engineering: Academic Press; 2002. 